Riwayat Artikel: Diterima 09 April 2017; Direvisi 16 Juli 2017; Disetujui 18 Juli 2017; dan Dipublikasikan 26 Juli 2017

\title{
PEMILIHAN AKUN MEDIA SOSIAL INSTAGRAM OLEH HOLIDAY INN BANDUNG
}

\section{THE SELECTION OF THE INSTAGRAM SOCIAL MEDIA ACCOUNT BY HOLIDAY INN BANDUNG}

\author{
Ajeng Jayanti Satyadewi, Hanny Hafiar, Aat Ruchiat Nugraha \\ (ajengjayantis@gmail.com, hannyhafiar@gmail.com, aatruchiat.nugraha@gmail.com) \\ (Fakultas Ilmu Komunikasi, UNPAD)
}

\begin{abstract}
Abstrak
Perkembangan teknologi informasi dalam lembaga perhotelan menjadi sangat penting untuk diadopsi dalam rangka meningkatkan kualitas layanan terhadap calon pelanggannya. Tujuan penelitian ini adalah untuk mengetahui perencanaan komunikasi yang melalui proses share, optimize, manage, dan engage dalam Instagram @holidayinnbandung. Metode penelitian yang digunakan metode penelitian deskriptif kualitatif dan landasan konsep yang digunakan The Circular Model of SOME dari Regina Lutrell. Hasil penelitian menunjukkan perencanaan komunikasi melalui Instagram @holidayinnbandung cukup optimal, proses share pemilihan Instagram dilatarbelakangi oleh keberhasilan penggunaan hashtag oleh IHG internasional. Untuk proses optimize perencanaan diawali dari promo yang dibuat melalui optimalisasi konten dengan memerhatikan aspek foto dan caption. Pada proses manage dilakukan media monitoring yang terdapat pada website-website analitik seperti pixlee dan insight Instagram, serta proses merespon feedback dari calon pelanggan dari follower dilakukan secara manual. Pada akhirnya untuk proses engage perencanaan dilakukan dengan menggunakan brand influencers dan membuat konten yang atraktif agar dapat menghibur dan berinteraksi dengan followers.
\end{abstract}

Kata Kunci: Instagram, Follower, Media Sosial

\section{Abstract}

The development of information technology in the hospitality institute is very important to be adopted in order to improve the quality of service to prospective customers. The purpose of this study was to determine the communication planning, through the process of share, optimize, manage, and engage in @holidayinnbandung Instagram.The research method is descriptive qualitative research methods and the foundation of the concept is The Circular Model of SOME. The results showed, the planning of communication via Instagram @ holidayinnbandung is quite optimal, sharing process of Instagram selection motivated by the successful use of hash tags by international IHG. Optimizing the planning process starting from the promo to be made by optimizing the content is done by looking at the aspects of a photo and caption. Engagement process planning is done using the brand influencers and create content that is attractive to be able to entertain and interact with the followers.

Keywords: Instagram, Follower, Social Media

\section{Pendahuluan}

Kehadiran teknologi informasi berupa social media telah membawa perubahan terhadap kehidupan manusia, terutama pada aspek perilaku, yang di mana kegiatan-kegiatan manusia semakin dipermudah. Kegiatan tersebut diantaranya adalah penyampaian pesan untuk kepentingan peningkatan ekonomi dalam hal meraih keuntungan melalui pelayanan jasa komunikasi dan informasi yang cepat

dan up date. Pelayanan jasa komunikasi dan informasi yang dikelola dan dimanfaatkan oleh suatu perusahaan yaitu menggunakan aplikasi social media seperti facebook, twitter, whatapps, path, line, dan instragram. Aplikasi Instagram merupakan aplikasi yang cukup sederhana karena hanya menampilkan gambar-gambar dan video dalam durasi tertentu dengan diberikan ruang untuk menulis dan 
berkomentar bagi orang yang menjadi pengelola maupun followers.

Mengelola sebuah aktivitas komunikasi lewat media sosial ternyata tidak sesederhana moto Instagram yang merupakan 'instant capture'. Terdapat seperangkat elemen yang sirkuler yang dapat mempengaruhi keberhasilan suatu perusahaan dalam mengelola media sosial yang dalam hal ini adalah Instagram. Public Relations Practioner harus mengetahui apa benar target sasaran yang ia miliki memang berada tepat pada Instagram, selain hanya merencanakan konten-konten yang dibagikan, ia juga harus mengelola hubungan real time dengan followers atau fansnya. Lebih jauh dari itu ia harus selalu berusaha untuk melakukan interaksi yang dapat mengikat followers dengan perusahaan untuk mencapai tingkatan engagement yang di tuju oleh perusahaan.

Holiday Inn Bandung telah memiliki akun Instagram sejak tahun 2013, namun karena keterbatasan tenaga kerja yang dimiliki akun Instagram tersebut tidak terlalu aktif sehingga tidak banyak mendapatkan perhatian dari igers, sebutan bagi para pengguna Instagram. Namun sejak keberadaan E-commerce di hotel tersebut, terdapat perubahan signifikan yang terlihat pada jumlah followers (sebutan bagi igers yang mengikuti akun instragram suatu akun lain) Instagram @holidayinnbandung yaitu sebanyak 2607 followers kenaikan tersebut mencapai lebih dari 2000 followers dalam kurun waktu 1 tahun. Instagram sendiri dinilai sebagai media sosial yang paling berperan penting bagi Holiday Inn Bandung. Menurut Malinda selaku Public Relations Manager hotel tersebut berpendapat bahwa zaman sekarang sudah makin maju dan demikian dengan orang-orangnya, mereka lebih tertarik dengan berita yang berbentuk 'foto' ketimbang yang hanya teks saja, Instagram sendiri memiliki popularitas yang sangat baik maka dari itulah
Instagram digunakan sebagai media sosial utama mereka.

Renda mengatakan bahwa dalam mengelola Instagram @ holidayinnbandung beliau selalu melakukan tahapan perencanaan terlebih dahulu dimana terdapat empat tahapan yaitu share, optimize, manage, engage. Pada tahapan share, Holiday Inn Bandung telah memilih Instagram dan juga menentukan target sasaran yang mereka kehendaki seperti dibahas diatas bahwa Holiday Inn Bandung memilih Instagram karena menyadari perubahan interest khalayak dari media massa tertulis menjadi media massa digital atau internet.

Pada tahapan optimize, Holiday Inn Bandung memulai perencanaan kontennya dari membuat promo untuk setiap bulannya, mempersiapkan konten yang akan di posting, dan juga photo taking untuk mengoptimalkan konten yang akan di share. Setelah konten-konten dipersiapkan, lalu dibuatlah timeline schedule untuk menentukan jadwal konten yang akan di share. Beliau menambahkan, 'Timeline schedule itu gunanya untuk maintain konten-konten yang mau di post, kan gak mungkin kita share promo atau konten yang sama terus-terusan'.

Konten yang dipersiapkan pun sangat beragam dan tidak selalu berisikan promo, bahkan posting-annya lebih sering berisikan life quotes, peringatan hari-hari besar baik nasional ataupun internasional, campaign atau kegiatan csr yang dilakukan oleh hotel, dan juga profil-profil pegawai Holiday Inn Bandung.

Pada tahapan manage, demi mengetahui performa Instagram @holidayinnbandung dengan baik, Holiday Inn Bandung pun rutin mengunjungi website-website analitik guna mengetahui bagaimana performa Instagram perusahaan tersebut. Website analitik yang digunakan adalah iconosquare.com. Untuk tahapan engage, Holiday Inn Bandung juga kerap mengadakan kerjasama dengan 
foodstagram (akun yang membahas mengenai kuliner-kuliner terkenal) terkenal atau selebgram (orang-orang yang terkenal dan memiliki jumlah followers sangat banyak di Instagram) sebagai bagian dari brand influencers untuk menarik khalayak yang lebih luas dan banyak lagi strategi menarik yang diterapkan oleh ecommerce hotel tersebut terhadap Instagram @ holidayinnbandung.

Namun perencanaan yang dilakukan sedemikian rupa dan jumlah followers yang terus meningkat tersebut tidak diimbangi dengan aspek engagement yaitu love rate, talk rate, dan spread rate yang baik pula. Presentase yang didapatkan dari ketiga aspek engagement tersebut hampir tidak pernah melebihi angka 1\%. Hal tersebut tidak berbanding lurus jika dibandingkan dengan pertumbuhan followers yang dapat melebihi $30 \%$ di setiap bulannya.
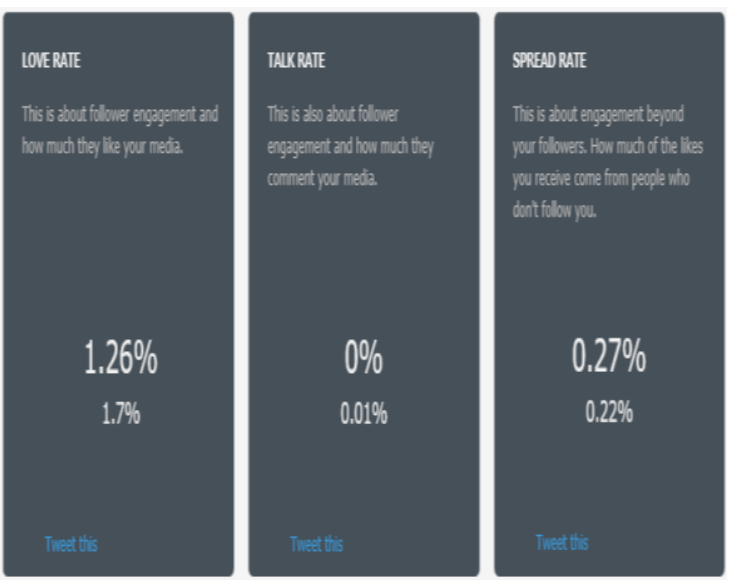

Gambar 1. Engagement score yang diperoleh Instagram @ holidayinnbandung pada Januari 2016

(Sumber:https://www.iconosquare.com/hol idayinnbandung)

Dari data diatas, kondisi tersebut menarik perhatian peneliti, mengingat bahwa dari proses perencanaan Instagram yang diketahui oleh peneliti bahwa Instagram tersebut telah dipersiapkan melalui beberapa tahapan dan dengan konten yang beragam. Berdasarkan latar belakang diatas, peneliti tertarik untuk melakukan penelitian mengenai bagaimana perencanaan komunikasi media sosial Instagram yang dilakukan oleh $E$ commerce Executive Holiday Inn Bandung dalam meningkatkan engagement dengan khalayaknya dengan focus penelitian adalah 'Bagaimana Perencanaan Komunikasi Melalui Instagram @holidayinnbandung yang dilakukan oleh E-commerce Executive Holiday Inn Bandung?'

Selanjutnya, terdapat beberapa literasi yang dapat dijadikan landasan konsep dalam riset ini. Menurut Donald Byker dan Loren J. Anderson, Komunikasi (manusia) adalah berbagi informasi antara dua orang atau lebih. Menurut Willian I. Gorden, Komunikasi secara ringkas dapat didefinisikan sebagai transaksi dinamis yang melibatkan gagasan dan perasaan. Sedangkan menurut Karl. Erik Rosengren, komunikasi adalah interaksi subjektif purposive melalui Bahasa manusia yang berartikulasi ganda berdasarkan simbolsimbol (dalam Mulyana, 2007: 76).

Menurut Mulyana (2007: 77), para pakar tersebut mendefinisikan komunikasi sebagai proses karena komunikasi merupakan kegiatan yang ditandai dengan tindakan, perubahanm pertukaran, dan perpindahan dimana terdapat kontinuitas dari setiap unsurnya.

Menurut Willian H. Newman (dalam Majid, 2006: 15), perencanaan adalah menentukan apa yang akan dilakukan. Perencanaan mengandung rangkaianrangkaian putusan yang luas dan penjelasan-penjelasan dari tujuan, penentuan kebijakan, penentuan program, penentuan metode-metode dan prosedur tertentu dan penentuan kegiatan berdasarkan jadwal sehari-hari. Menurut Kamus Besar Bahasa Indonesia (KBBI), perencanaan berasal dari kata rencana, yang berarti (1) cerita; (2) rancangan; buram (rangka sesuatu yang akan dikerjakan); (3) acara (pembicaraan); program. Sedangkan perencanaan sendiri memiliki arti proses, cara, perbuatan 
merencanakan

(merancangkan)

(http://kbbi.web.id/rencana, diunduh pada tanggal 8 Desember 2016 pukul 9.34 WIB).

Sementara itu, teknologi Informasi adalah suatu teknologi yang digunakan untuk mengolah data, termasuk memproses, mendapatkan, menyusun, menyimpan, dan memanipulasi data dalam berbagai cara untuk menghasilkan informasi yang berkualitas, yaitu informasi yang relevan, akurat dan tepat waktu, yang digunakan untuk keperluan pribadi, bisnis (Gemiharto, 2015). Salah satu jenis teknologi informasi adalah media sosial.

Social media adalah sebuah media online dimana para penggunanya dapat dengan mudah berpartisipasi, berbagi dan menciptakan isi meliputi blog, social network atau jejaring sosial, wiki, forum dan dunia virtual lainnya. Blog, jejaring sosial dan wiki mungkin merupakan bentuk media social yang paling umum digunakan oleh masyarakat diseluruh dunia (Ardianto, 2011: 165). Menurut Ardianto (2011: 165), social media juga begitu mempengaruhi masyarakat Indonesia. Jumlah pengguna yang tinggi ini tentu saja dapat menjadi perhatian para praktisi Public Relations. Social Media jika dikaji melalui perspektif PR, tentu akan memberikan keuntungan bagi PR untuk berkomunikasi secara interaktif dan meluas terhadap publiknya. Media sosial memungkinkan PR untuk menggunakannya sebagai tools PR yang bersifat two-way or multi-directional communication pada publiknya. PR dapat menciptakan percakapan, memberikan informasi dan menunjukan kehadiran yang baik dari organisasi.

Dalam situs resmi instagram, www.instagram.com, terdapat definisi yang dijabarkan oleh perusahaan ini: instagram is a fun and quirky way to share your life with friends through a series of pictures. Snap a photo with your mobile phone, then choose a filter to transform the image into a memory to keep around forever.'

Instagram membangun suatu profil publik atau semi publik dalam sistem yang terbatas, mengartikulasikan daftar pengguna lain dengan siapa saja mereka berbagi, melihat dan menelusuri daftar kolega mereka dan daftar kolega yang dibuat oleh orang lain dalam sistem. Mengijinkan dan menganjurkan seluruh pengguna untuk membuat, berbagi dan menyebarkan informasi dan gambar yang menekankan berbagi konten antara pengguna dan kolaborasi secara online. Hal ini adalah bentuk aplikasi yang dinamis, fleksibel dan interaktif yang keseluruhannya dapat disebut sebagai desain.

Selanjutnya, The Circular Model of Some merupakan sebuah model yang diciptakan oleh Regina Luttrell untuk memudahkan para praktisi media sosial untuk melakukan perencanaan komunikasi pada media social. 'I would like to introduce such a model for social media planning: the Circular Model of Some for Social Communication--Share, Optimize, Manage, Engage--.' (Luttrell, 2015: 40) di mana Luttrell memperkenalkan sebuah model untuk perencanaan media sosial yaitu model sirkuler Some untuk komunikasi sosial yang terdiri dari membagikan, mengoptimalkan, mengelola, dan melibatkan.

Terdapat empat aspek dalam model ini, keempat aspek tersebut memiliki kekuatan dalam bagiannya masing-masing, tetapi bersama-sama aspek ini memungkinkan praktisi untuk mengembangkan strategi yang solid. Model ini sengaja dibuat melingkar, alasannya adalah bahwa media sosial adalah percakapan yang terus berkembang. Ketika sebuah perusahaan berbagi (sharing) sesuatu mereka juga dapat mengelola (manage) atau terlibat (engage) dan bahkan mengoptimalkan (optimize) pesan mereka secara bersamaan. Oleh karena itu model linier gagal untuk 
menyatukan apa yang diperlukan untuk strategi tersebut.

Berikut adalah penjelasan mengenai the Circular model of Some menurut Regina Luttrell dalam bukunya Social Media:

- $\quad$ Share: Dimana pemirsa saya? Jenis jaringan apa yang mereka gunakan? Di mana kita harus berbagi konten? Sangat penting bagi praktisi sosial media untuk memahami bagaimana dan di mana konsumen mereka berinteraksi. Ini adalah kesempatan perusahaan untuk menghubungkan, membangun kepercayaan, dan mengidentifikasi saluran yang memungkinkan interaksi yang tepat.

- Optimize: Apakah ada masalah yang perlu ditangani? Jenis konten apa yang harus dibagikan? Apakah kita memiliki orang yang berpengaruh terhadap perusahaan dan pendukung? Di mana kita sedang diperbincangkan dan bagaimana? Mengoptimalkan setiap rekaman percakapan adalah hal yang terpenting. Sebuah plan komunikasi yang kuat yang dioptimalkan dengan baik menghasilkan dampak maksimum pada pesan, brand, dan juga nilai.

- Manage: Apa pesan yang relevan yang harus kita kelola, pantau, dan ukur? Dengan mengatur sistem manajemen media seperti dengan Perusahaan hootsuite dimana dapat terus mengikuti percakapan yang terjadi di real-time, menanggapi konsumen langsung, mengirim pesan pribadi, berbagi link, memantau percakapan dan mengukur keberhasilan/kegagalan. Matriks merupakan bagian integral dalam mengelola strategi sosial. Sebagai praktisi kita harus menggambarkan nilai upaya dan melaporkan kembali ke tingkat eksekutif.

- Engage: Siapa yang harus kita libatkan dan bagaimana? Apakah kita ingin konsumen untuk mengambil tindakan pada apa yang telah kita bagikan? Jika demikian, apa yang kita ingin mereka lakukan? Mengolah strategi engagement merupakan hal yang sulit, tetapi ketika perusahaan menyadari manfaat dari keterlibatan otentik hubungan yang tepat dapat dibangun.

\section{Metodologi}

Pada penelitian ini peneliti menggunakan metode deskriptif kualitatif. Metode tersebut sesungguhnya belum benar-benar' kualitatif, karena pengaruh arus berpikir kuantitatif masih kuat dan mengakar pada penelitian ini. Penelitian ini berbeda pada cara memperlakukan teori, yaitu lebih banyak dipengaruhi oleh pandangan-pandangan deduktif-kuantitatif. Bahkan menurut Bungin, didalam sejarah penelitian kualitatif, metode ini sendiri tidak sepenuhnya mengakar pada penelitian kualitatif, namun hanya kebiasaan dan pengaruh pandangan kuantitatif-kualitatif sajalah yang akhirnya melahirkan tipe penelitian deskriptif kualitiatif tersebut. Pada umumnya peneliti deskriptif-kualitatif berupaya keras agar pembahasan mereka lebih cenderung kualitatif daripada kuantitatif, dengan mendekati makna dan ketajaman analisislogis dan juga dengan cara menjauhi statistik 'sejauh-jauhnya', sehingga metode penelitian ini diterima sebagai salah satu tipe penelitian kualitatif (Bungin, 2008: 23).

Paradigma yang digunakan oleh peneliti adalah paradigma positivisme. Menurut Salim (2006: 68), paradigma positivisme merupakan paradigma yang muncul paling awal dalam dunia ilmu pengetahuan. Keyakinan dasar aliran ini berakar pada paham ontologi realisme yang menyatakan bahwa realitas berada (exist) dalam kenyataan dan berjalan sesuai dengan hukum alam (natural laws). Penelitian berupaya mengungkapkan kebenaran realitas yang ada, dan bagaimana realitas tersebut senyatanya berjalan.

Teknik sampling yang digunakan oleh peneliti adalah teknik purposive sampling yaitu teknik pengambilan sampel sumber data dengan pertimbangan tertentu 
misalnya orang tersebut dianggap paling tahu tentang apa yang kita harapkan, atau mungkin dia sebagai objek/situasi sosial yang diteliti (Faisal dalam Sugiyono, 2009: 56). Berdasarkan teknik sampling purposive, maka peneliti menentukan subjek penelitian berdasarkan pertimbangan-pertimbangan khusus disesuaikan dengan konteks penelitian dan fokus penelitian yang diteliti.

Teknik pengumpulan data yang digunakan oleh peneliti adalah wawancara kepada narasumber yang sudah ditentukan terlebih dahulu, observasi langsung ke Holiday Inn Bandung, dan dokumentasi dimana peneliti mengumpulkan dokumendokumen yang berasal dari buku, skripsi, jurnal, dan artikel berkaitan dengan humas dan juga media sosial. Sementara analisis dokumen berasal dari, media promosi, publikasi, artikel elektronik, dan foto-foto.

Bogdan (Sugiyono, 2009: 88) mengatakan analisis data sendiri adalah proses mencari dan menyusun secara sistematis data yang diperoleh dari hasil wawancara, catatan lapangan, dan bahanbahan lain, sehingga dapat mudah difahami, dan temuannya dapat diinformasikan kepada orang lain. Analisis data dilakukan dengan mengorganisasikan data, menjabarkannya ke dalam unit-unit, melakukan sintesa, menyusun kedalam pola, memilih mana yang penting dan yang akan dipelajari, dan membuat kesimpulan yang dapat diceritakan kepada orang lain. Analisis data yang dilakukan peneliti adalah reduksi data, penyajian data, dan verifikasi data.

Salah satu cara paling penting dan mudah dalam uji keabsahan hasil penelitian adalah dengan melakukan triangulasi (Bungin, 2008: 256). Mengacu kepada Denzin (dalam Bungin, 2008:257) maka pelaksaan teknis dari langkah pengujian keabsahan ini dapat memanfaatkan peneliti, sumber, metode, dan teori. Pada penelitian ini peneliti akan menggunakan jenis triangulasi sumber yaitu Detta Rahmawan selaku Dosen
Program Studi Manajemen Komunikasi, Fakultas Ilmu Komunikasi, Universitas Padjajaran dan pengamat media sosial.

\section{Hasil dan Pembahasan}

Berdasarkan hasil penelitian ComScore yang bekerjasama dengan Indonesia Digital Measurement Consortium (IDMC) dan Badan Ekonomi Kreatif (Berkraf) mengeluarkan data mengenai jumlah pengunjung sebuah situs dan aplikasi di Indonesia pada periode Januari 2017 sebagaimana yan dirilis oleh Pikiran Rakyat Edisi Kamis, 6 April 2017, diantaranya adalah:

\begin{tabular}{|c|c|c|c|}
\hline \multirow{2}{*}{$\begin{array}{c}\text { Ra- } \\
\text { nk }\end{array}$} & APP & $\begin{array}{c}\text { Total Mobile } \\
\text { Pengun- } \\
\text { jung } \\
\text { (dalam } \\
\text { juta) }\end{array}$ & Pencapaian \\
& $\begin{array}{c}\text { Total } \\
\text { Internet: } \\
\text { Total } \\
\text { Audience } \\
\text { (Mobile }\end{array}$ & 46.130 & 100 \\
\hline 1 & $\begin{array}{c}\text { Geogle } \\
\text { Play }\end{array}$ & 44.292 & 96 \\
\hline 2 & $\begin{array}{c}\text { WhatsApp } \\
\text { Messenger }\end{array}$ & 35.799 & 77.6 \\
\hline 3 & You Tube & 35.627 & 77.2 \\
\hline 4 & BBM & 34.748 & 75.3 \\
\hline 5 & $\begin{array}{c}\text { Google } \\
\text { Search }\end{array}$ & 30.442 & 66 \\
\hline 6 & Gmail & 28.584 & 62 \\
\hline 7 & Line & 27.613 & 59.9 \\
\hline 8 & Instagram & 23.876 & 51.8 \\
\hline 9 & Facebook & 22.268 & 48.3 \\
\hline 10 & $\begin{array}{c}\text { Google } \\
\text { Maps }\end{array}$ & 20.865 & 45.2 \\
\hline 19 & 10 Besar & \\
\hline
\end{tabular}

Tabel 1. 10 Besar Aplikasi Mobile Devices di Indonesia per Januari 2017

Sumber: comScore Mobile Metrix

Dari data tabel di atas, menunjukkan bahwa aplikasi Instagram termasuk aplikasi yang disukai oleh masyarakat Indonesia. Hal ini terbukti karena karakteristik masyarakat Indonesia yang 
menyukai kegiatan-kegiatan eksis diri untuk diketahui oleh orang lain. Maka, aplikasi Instagram menjadi salah satu pilihan yang baik untuk digunakan sebagai media sosialisasi diri karena tidak banyak mengandung hater dan hanya menampilkan gambar dan foto yang terbatas.

Perangkat Instagram ini merambah pada pengelola lembaga/perusahaan yang ingin mempromosikan produk baik berupa barang maupun jasa. Dengan kesederhanaan yang terdapat pada menu Instagram, kini para pengelola informasi dan marketing suatu perusahaan yang terpincut dan beralih melakukan promosinya dengan memanfaatkan Instagram. Akuntabilitas bisa digunakan sebagai media perusahaan membangun image dan network terhadap stakeholder (Nassaluka, Hafiar \& Priyatna, 2016). Hal ini juga yang dilakukan oleh Hotel Holiday Inn Bandung yang memanfaatkan media social Instagram dalam upaya meningkatkan tingkat hunian hotel sebagai bentuk kualitas layanan informasi yang tercepat dalam melayani pelanggannya.

Proses Share dalam Perencanaan Komunikasi melalui Instagram @holidayinnbandung:

Berdasarkan hasil wawancara yang dilakukan oleh peneliti mengenai proses share dalam perencanaan komunikasi melalui Instagram @holidayinnbandung, terdapat 3 tahapan yaitu latar belakang pemilihan Instagram, target sasarannya, dan bagaimana cara Holiday Inn Bandung dalam membangun kepercayaan publik. Berikut adalah tahapan-tahapan yang dilakukan dalam proses share:

1. Latar belakang penggunaan Instagram Holiday Inn Bandung adalah berasal dari mandat IHG pusat yang berawal dari keberhasilan penggunaan hashtag \#ihgfoodie sehingga IHG menjadikan Instagram sebagai salah satu media sosial yang harus dimiliki oleh seluruh Holiday Inn Bandung, selain itu juga karena minat masyarakat yang semakin digital dan sangat tertarik terhadap bentuk visual seperti halnya foto atau video.

2. Khalayak yang menjadi target sasaran disamakan dengan positioning hotel yaitu keluarga dengan demografis menengah keatas dan juga traveler, business man, atau pekerja kantoran dengan usia 20-55 tahun dengan geografis kota Jakarta dan Bandung.

3. Holiday Inn Bandung membangun kepercayaan publik dengan melakukan beberapa upaya yaitu dengan mem-post konten-konten tertentu yang dapat menumbuhkan kepercayaan publik terhadap perusahaan diantaranya adalah review dari tamu, me-repost foto yang di post oleh tamu, dan juga mem-post foto karyawan yang menjadi bagian dari Holiday Inn Bandung.

Proses Optimize dalam Perencanaan Komunikasi melalui Instagram @ holidayinnbandung:

Berdasarkan hasil wawancara yang dilakukan oleh peneliti mengenai proses optimiize dalam perencanaan komunikasi melalui Instagram @holidayinnbandung, terdapat 3 tahapan yaitu perencanaan komunikasi, tahapan perencanaan komunikasi, dan optimalisasi pesan. Berikut adalah tahapan-tahapannya:

1. Pada tahapan perencanaan komunikasi, Holiday Inn Bandung menggunakan timeline schedule sebagai panduan perencanaan instagramnya. Listen and Learn yang seharusnya dilakukan setiap perencanaan hanya dilakukan ketika terdapat konten yang mendapatkan Feedback yang baik. Holiday Inn Bandung juga tidak mempraktikkan 'take part in authentic conversations' dalam perencanaan komunikasinya. Karena pada prinsipnya, komunikasi pemasaran menjadi inti bagaimana perusahaan memanfaatkan sebuah strategi, perencanaan, pelaksanaan dan evaluasi dalam mempertahankan atau mengembangkan perusahaan di dunia bisnis (Reza, 2016). 
2. Perencanaan timeline schedule terdiri dari beberapa tahapan. Pertama-tama mengumpulkan promo dari setiap divisi dan diajukan approval atau persetujuan kepada general manager, ketika approval tersebut diterima lalu dilakukan proses pemotretandan di buat design untuk semua media promosi yang Holiday Inn Bandung gunakan salah satunya adalah Instagram. Kemudian hasil design tersebut di buat persetujuannya atau approval ke tingkat director of sales dan general manager, ketika design dan promo tersebut di setujui lalu di distribusikan lah semua promo ke pihak-pihak yang bersangkutan salah satunya adalah untuk media sosial. Promopromo yang telah dibuat untuk satu bulan kedepan tersebut lalu di masukkan kedalam timeline schedule untuk membagi-bagi konten yang akan di post di Instagram @ holidayinnbandung.

3. Dalam mengoptimalisasi pesan, Holiday Inn Bandung mengoptimalisasikan konten yang akan disebar dengan menyesuaikan gaya fotografi dan caption yang disesuaikan dengan standarisasi dan positioning hotel. Waktu dalam mem-posting mengikuti habit pekerja yaitu pagi saat sebelum bekerja, siang saat jam istirahat, dan malam setelah jam kerja berakhir. Waktu terbaik untuk mem-posting yang ada pada insight tidak digunakan padahal sangat membantu untuk proses optimalisasi penyebaran pesan.

Proses Manage dalam Perencanaan Komunikasi melalui Instagram @holidayinnbandung:

Berdasarkan hasil wawancara yang didapat, pada proses manage Holiday Inn Bandung melakukan tiga tahapan yaitu media monitoring, evaluasi, dan pengelolaan feedback, yaitu:

1. Pada tahapan media monitoring, media monitoring dilakukan menggabungkan beberapa website analitik yaitu unionmatrics, pixlee, dan Insight Instagram. Media monitoring yang dilakukan meliputi followers, hashtag, top post, gender, age, dan top locations. Holiday Inn Bandung sudah sadar akan pentingnya menggunakan website analytic untuk melakukan media monitoring.

2. Pada proses evaluasi dibahas mengenai followers, engagement, kontenkonten yang di post, feedback yang masuk, dan juga waktu terbaik untuk memposting. Evaluasi yang telah di dapatkan tersebut tidak menjadi bahan pertimbangan untuk perencanaan selanjutnya dan seringkali tidak dijadikan perbaikan. Sudah tidak ada lagi aspek engagement di dalam evaluasi yang dilakukan.

3. Pengelolaan feedback dilakukan secara manual lewat aplikasi Instagram, tidak menggunakan social media dashboard. Pengelolaan feedback tidak dilakukan dengan cepat bahkan sering kali terabaikan dan tidak dibalas, dari hasil observasi kerap kali terdapat commentcomment yang masuk tidak dibalas padahal Holiday Inn Bandung sendiri mengatakan bahwa dalam waktu maksimal 1x24 jam semua feedback yang masuk baik berupa comment, ataupun direct message harus sudah dibalas. Holiday Inn Bandung juga jarang melakukan 'real time interactions'. Oleh karena itu dirasakan perlu untuk mengevaluasi setiap kinerja karyawan, sesuai dengan pernyataan: diperlukan adanya kesungguhan pelaksanaan evaluasi pekerjaan di setiap unit kerja (Aristi dan Hafiar, 2014). Oleh karena itu, arus informasi dalam perusahaan haruslah berjalan lancar. Informasi dan salurannya dapat dirancang agar para bawahan memahami bagaimana pekerjaan yang berkaitan dengan tugas dalam organisasi, serta mengapa mereka melaksanakan tugas, untuk kemudian dapat dihayati bagaimana pekerjaan mereka membantu upaya organisasi mencapai sasaran (Suparna dan Winoto, 2013). 
Proses Engage dalam Perencanaan Komunikasi melalui Instagram @ holidayinnbandung:

Berdasarkan hasil wawancara yang didapat, dalam proses engage Holiday Inn Bandung melakukan pendekatan kepada stakeholder yaitu kepada brand influencers dan khalayak, seperti:

1. Brand Influencers. HolidayInn Bandung tidak memiliki brand influencersyang tetap namun Holiday Inn Bandung menggunakan selebgram atau publik figur sebagai brand influencers-nya dengan melakukan stay experience di hotel tersebut. Lewat stay experience tersebut publik figur akan membagikan pengalamannya selama stay experience kepada followers-nya. Konten-konten yang dibagikan pun dapat disesuaikan dengan kebutuhan hotel. Namun kegiatan Brand influence terkadang kurang maksimal karena tidak di awasi pada pelaksanaannya.

2. Audience. Holiday Inn Bandung berupaya melakukan engagement dengan khalayak atau followers dengan mem-post konten-konten atraktif dan menghibur seperti kuis interaktif, photo or video contest, event-event yang dilakukan di Holiday Inn Bandung ataupun yang sedang berlangsung di kota Bandung bahkan di dunia, hari-hari besar atau hari nasional yang sedang berlangsung, Sejarah Holiday Inn Bandung atau Kota Bandung sendiri, hingga life quote yang pas untuk kehidupan sehari-hari.

\section{Penutup}

Berdasarkan hasil penelitian dapat disimpulkan bahwa: proses share yang dilakukan Holiday Inn Bandung pada perencanaan komunikasi Instagram @holidayinnbandung dilatar belakangi oleh keberhasilan penggunaan hashtag dari brand IHG internasional dan ketertarikan publik yang berubah kepada sesuatu yang bersifat visual dan daring. Holiday Inn Bandung juga mempersiapkan kontenkonten untuk membangun kepercayaan public; proses optimize yang dilakukan Holiday Inn Bandung pada perencanaan komunikasi Instagram @holidayinnbandung ditunjukkan melalui tahapan perencanaan yang dimulai dari promo bukan dari masalah atau isu hasil listen and learn dan take part in authentic conversation yang seharusnya dilakukan ketika akan dilakukan perencanaan konten.

Cara mengoptimalisasikan pesan yang dipilih lewat caption dan foto disajikan mengikuti karakteristik Holiday Inn Bandung yang elegan; proses manage yang dilakukan Holiday Inn Bandung pada perencanaan komunikasi Instagram @holidayinnbandung adalah dengan melakukan media monitoring dengan baik dengan menggunakan beberapa engine statistik untuk Instagram, namun ketika merespon feedback Holiday Inn Bandung sering kali lalai hingga tidak menjawab comment yang masuk, padahal hal tersebut sangat penting; proses engage yang dilakukan Holiday Inn Bandung pada perencanaan komunikasi Instagram @holidayinnbandung adalah dengan mempersiapkan konten-konten seperti kuis interaktif dan foto/video challenge untuk berinteraksi dengan khalayak atau followers, brand influencers tidak dipersiapkan dengan matang dan tidak di evaluasi setelahnya, engagement rate yang diraih kurang dari $2 \%$ di mana angka tersebut berada di tingkatan terendah yaitu pada level 1 dimana followers atau khalayak belum tertarik untuk memberikan feedback seperti likes, comment, apalagi menyebarkan @ holidayinnbandung.

Untuk melengkapi hasil penelitian ini, peneliti memberikan beberapa saran, yaitu: posisi Public Relations seharusnya berada di Top Management sehingga dapat berfungsi dengan lebih baik dan memiliki wewenang yang lebih besar; Target sasaran dipersempit mulai 20-40 tahun agar lebih sesuai dengan khalayak Instagram; menerapkan listen and learn dan take part in authentic conversation 
agar mengetahui masalah atau isu atau konten yang diinginkan khalayak.

\section{Daftar Pustaka}

Ardianto, E. (2011). Handbook of Public Relations. Bandung: Simbiosa Rekatama Media.

Bungin, B. (2008). Penelitian Kualitatif. Jakarta: Kencana.

Luttrell, R. (2015). Social Media. Maryland: Rowman \& Little Field.

Majid, A. (2006). Perencanaan Pembelajaran. Bandung: PT Remaja Rosdakarya.

Mulyana, D. (2007). Ilmu Komunikasi. Bandung: PT Remaja Rosdakarya.

Salim, A. (2006). Teori \& Paradigma. Yogyakarta: Tiara Wacana.

Sugiyono. (2009). Memahami Penelitian Kualitatif. Bandung: Alfabeta.

Aristi, N. \& Hafiar, H. (2014). Analisis Beban Kerja Tenaga Pendidik dan Kependidikan di Fakultas Y Universitas X. Jurnal Kajian Komunikasi, 2 (1), 53-60.
Gemiharto, I. (2015). Teknologi 4G-Lte Dan Tantangan. Jurnal Kajian Komunikasi, 3 (2), 212-220.

Nassaluka, E. U., Hafiar, H., \& Priyatna, C. C. (2016). Model Kemitraan PT. Holcim Indonesia Tbk. Profesi Humas, 1 (1), 22-34.

Reza, F. (2016). Strategi promosi penjualan. Jurnal Kajian Komunikasi, 4 (11), 64-74.

Suparna, P. R. T. S., \& Winoto, Y. (2013). Keterbukaan Komunikasi dalam Menciptakan Iklim Komunikasi yang Kondusif di Perpustakaan. Jurnal Kajian Informasi \& Perpustakaan, 1(2), 157-164.

http://kbbi.web.id/rencana (diakses pada tanggal 8 Desember 2016 pukul 9.34 WIB).

https://www.iconosquare.com/holidayinnb andung (diakses pada tanggal 28 November 2016 pukul 15.45 WIB). 